\title{
TRENDS AND CHALLENGES OF TRADITIONAL MEDICINE IN AFRICA
}

\author{
Abdullahi, Ali Arazeem \\ *Department of Sociology, University of Johannesburg, South Africa. \\ Email: kwaraeleven@yahoo.com
}

\begin{abstract}
Prior to the introduction of cosmopolitan medicine, traditional medicine used to be the dominant medical system available to millions of people in Africa in both rural and urban communities. However, the arrival of the Europeans marked a significant turning point in the history of this age-long tradition and culture. This paper examines the trends and challenges of traditional medicine in Africa. The impact of colonialism on African traditional medicine is also examined. Although the paper is on Africa, references are drawn around the world to buttress the growing demand for traditional medicine. The paper concludes that to minimise the current distrust between modern and traditional doctors and to achieve the objective of regulation, standardisation and cooperation, both traditional and modern doctors must acknowledge their areas of strengths and weaknesses from which they operate and be genuinely concerned about the difficult but necessary task of being human.
\end{abstract}

Key words: Traditional medicine, challenges, Africa

\section{Introduction}

Traditional medicine (TM), variously known as ethno-medicine, folk medicine, native healing, or complementary and alternative medicine (CAM), is the oldest form of health care system that has stood the test of time. It is an ancient and culture-bound method of healing that humans have used to cope and deal with various diseases that have threatened their existence and survival. Hence, TM is broad and diverse. Consequently, different societies have evolved different forms of indigenous healing methods that are captured under the broad concept of TM, e.g. Chinese, Indian and African traditional medicines. This explains the reason why there is no single universally accepted definition of the term. This notwithstanding, one of the most acceptable definitions of TM has been provided by the World Health Organisation (WHO). According to the World Health Organisation, TM is "the sum total of the knowledge, skills and practices based on the theories, beliefs and experiences indigenous to different cultures, whether explicable or not, used in the maintenance of health, as well as in the prevention, diagnosis, improvement or treatment of physical and mental illnesses" (WHO, 2000b:1). Traditional healer, on the other hand, is "a person who is recognised by the community where he or she lives as someone competent to provide health care by using plant, animal and mineral substances and other methods based on social, cultural and religious practices" (WHO, 2000a:11).

Prior to the introduction of the cosmopolitan medicine, TM used to be the dominant medical system available to millions of people in Africa in both rural and urban communities. Indeed, it was the only source of medical care for a greater proportion of the population (Romero-Daza, 2002). There are strong indications that traditional health care systems are still in use by the majority of the people not only in Africa but across the world. In Africa, the healers are variously addressed as Babalawo, Adahunse or Oniseegun among the Yoruba speaking people of Nigeria; Abia ibok among the Ibibio community of Nigeria; Dibia among the Igbo of Nigeria; Boka among the Hausa speaking people of Nigeria; and Sangoma or Nyanga among South Africans (Cook, 2009). In indigenous African communities, the traditional doctors are well known for treating patient holistically. They (the traditional doctors) usually attempt to reconnect the social and emotional equilibrium of patients based on community rules and relationships (Hillenbrand, 2006) unlike medical doctors who only treat diseases in patients. In many of these communities, traditional healers often act, in part, as an intermediary between the visible and invisible worlds; between the living and the dead or ancestors, sometimes to determine which spirits are at work and how to bring the sick person back into harmony with the ancestors. However, the arrival of the Europeans marked a significant turning point in the history of this age-long tradition and culture. In this paper, the trends and challenges of African traditional medicine are examined with emphasis on the efforts towards the integration of TM into the mainstream of health care systems.

\section{Once Upon a Time}

Discourses about the impact of colonialism in Africa are clouded by a mixture of 'fortune' and 'agony'. Some scholars (such as Curtin, 1989, 1998; Olsson, 2009) are of the opinion that the process of modernisation in Africa is 
intrinsically connected with foreign intervention particularly in areas of health and democracy. For example, Curtin (1998) argues that the period between 1840 and 1860 marked a significant and rapid innovation in tropical medicine, particularly, the invention of quinine to stem the scourge of malaria in the most endemic region of the world. From this point of view, the institutionalisation of the modern health care system can, therefore, be seen as one of the many 'legacies' of Western encroachment in Africa. On the contrary, there are those who believe that Western invasion was/is a set-back in the process of development in Africa (Achebe, 1958; Afisi, 2009; Offiong, 1980; Rodney, 1972) particularly in 'modes of knowledge production' (Taiwo, 1993: 891). These scholars mention slavery, capitalism, colonialism and imperialism, neo-colonialism and all forms of dominations and exploitations that were/are embedded in these epochs as major stumbling-blocks in the actualisation of indigenous African development. Indeed, the current political and socio-economic crises in Africa are attributed to colonialism and its attributes.

Similarly, while some critics of colonialism have focused on the economic and political impacts, others have shifted attention to the impact of colonialism on indigenous knowledge system (IKS) (Mapara, 2009) especially knowledge of medicine (Feierman, 2002; Konadu, 2008; Millar, 2004; Paul, 1977). Such arguments underscore the negative impact of colonialism on indigenous medicine. It is explained that the introduction of Western medicine and culture gave rise to 'cultural-ideological clash' which had hitherto created an unequal power-relation that practically undermined and stigmatised the traditional health care system in Africa because of the over-riding power of the Western medicine. This became manifested in South Africa during the Apartheid regime. According to Hassim et al. (http://www.alp.org.za):

... a century of colonialism, cultural imperialism and apartheid in South Africa have held back the development of African traditional health care in general and medicines in particular. During several centuries of conquest and invasion, European systems of medicine were introduced by colonisers. Pre-existing African systems were stigmatised and marginalised. Indigenous knowledge systems were denied the chance to systematise and develop.

In some extreme cases, TM was outrightly banned. For instance, the South African Medical Association outlawed traditional medical system in South Africa in 1953 (Hassim, et al. n.d). In addition, the Witchcraft Suppression Act of 1957 and the Witchcraft Suppression Amendment Act of 1970 also declared TM unconstitutional thereby disallowing the practitioners from doing their business in South Africa (Hassim et al. n.d.). The ban of TM was partially based on the belief that the conception of disease and illness in Africa was historically embedded in "witchcraft" where, in Western knowledge, witchcraft reinforces "backwardness", "superstition" and "dark continent". However, recent studies have shown that etiologies of illnesses in Africa are viewed from both natural and supernatural perspectives (Bello, 2006; Erinosho, 1998, 2005, 2006; Jegede, 1996; Oke, 1995). The subjugation of TM continued in most African countries even after independence. Indeed, local efforts were initiated to challenge the condemnation and stigmatisation of TM in some African communities during and after colonialism. Erinosho (1998; 2006) reported that the first protest against the marginalisation of TM in Nigeria is dated back to 1922 when a group of native healers insisted that their medicine be legally recognised.

In post independence Africa, concerted efforts have been made to recognise TM as important aspect of health care delivery system in Africa. For instance, in Nigeria, the Federal Government through the Ministry of Health encouraged and authorised the University of Ibadan in 1966 to conduct research into the medicinal properties of local herbs with a view to standardise and regulate TM (WHO, 2001). In 1980s, policies were put in place to accredit and register native healers and regulate their practice. In 1981, the National Council on Health (NCH) unanimously approved the establishment of a National Traditional Healers' Board at the Federal level involving representatives of the Federal and State governments which was to be duplicated at the State levels. Under the present health care reform of the Federal Government of Nigeria, TM is purportedly recognised as an important component of health care delivery system especially at the primary care level (Federal Ministry of Health (FMoH), 2004). The Federal Government of Nigeria has established the Nigeria Natural Medicine Development Agency (NNMDA) to study, collate, document, develop, preserve and promote Nigerian traditional medicine products and practices and to also fast-track the integration of the TM into the mainstream of modern health care system in line with happenings in China and India (The Sun news online, 2010). However, the lingering mutual distrust between allopathic and traditional practitioners in Africa has continuously hampered and thwarted the process of integration and cooperation between traditional and modern medicines (Nevin 2001) as well as the difficulties in regulating traditional medical practices. On the whole, Western-trained physicians appear unwilling to allow TM and their practitioners included in the official system of medical care in Africa. For instance, Ebomoyi (2009) found out that Nigerian medical students have reservation for the integration of TM into the mainstream of health care provision in the country. This is an indication that not much is being done in medical schools to encourage the teaching of TM as they keep unfolding in some parts of the world.

\section{Evidences of Growing Demand}

Although, "passionate ambivalence" towards TM has been noted in Africa (Bello, 2006; Feierman, 2002), TM is still in use in modern day Africa after hundreds of years of its existence without much reported cases of adverse effects (Okigbo and Mmeka, 2006: 83). In countries like Ghana, Mali, Zambia and Nigeria, the first line of treatment for $60 \%$ of children with high fever resulting from malaria is the use of herbal medicine (WHO, 2002b). Carpentier et al. 
(1995) discovered an increasing demand for TM in the case of rheumatic and neurological complaints in BurkinaFaso. In Ghana, about 70\% of the population depends primarily on TM (Roberts, 2001). About 27 million South Africans (usually the black South Africans) use TM to treat a variety of ailments (Lekotjolo, 2009; Mander, et al. 2007). Makundi et al. (2006) found out that traditional health care has contributed very significantly to the treatment of degedege (convulsions) in rural Tanzania. In some instances, patients use TM simultaneously with modern medicine in order to alleviate sufferings associated with disease and illness. Amira and Okubadejo (2007) reported that a significant number of hypertensive patients receiving conventional treatment at the tertiary health facility in Lagos, Nigeria, also used CAM therapies.

Similarly, the growing demand for TM in Europe, Asia and America has also been documented. It has been revealed that between $40 \%$ and $60 \%$ of the population in Western Pacific Region use TM to treat various diseases (WHO, 2001). At one time or the other, about $60 \%$ of the population in Hong Kong has consulted traditional health practitioners. There are indications that CAM is gaining widespread acceptability in Australia, France and Canada with $46 \%, 49 \%$ and $70 \%$ of the population respectively using TM (WHO, 2002a; Amzat and Abdullahi, 2008). In the United Kingdom (UK), almost $40 \%$ of the physicians make some alternative referrals (WHO, 2002a). The WHO's regional office for Americas' (AMRO/ PAHO) report demonstrates that $71 \%$ and $40 \%$ of populations in Chile and Colombia respectively have used TM (Amzat and Abdullahi, 2008).

As a result, $\mathrm{WHO}$ has acknowledged the contributions of traditional healers to the overall health delivery particularly in developing countries (see WHO, 2001; 2002a; 2002c). According to the World Health Organisation the native healers have contributed to a broad spectrum of health care needs that include disease prevention, management and treatment of non-communicable diseases as well as mental and gerontological health problems (WHO, 2001). There are also increasing evidences that TM is effective in the management of chronic illnesses (Thorne et al. 2002). In fact, TM is taught as part of school curriculum activities in medical schools in the USA (Wetzel et al. 1998). Perhaps, some important questions to ask are: Why the growing demands for TM across the world? And why the sudden concerns for assessing and evaluating the effectiveness of TM?

A number of factors have been identified as responsible for the widespread use of TM and the sudden concern for assessing and evaluating the effectiveness of the medicine across the world. Research has shown that a number of traditional medicines are important and effective therapeutic regimens in the management of a wide spectrum of diseases some of which may not be effectively managed using Western medicines. According to Mander et al. (2007: 190) among South African black population, TM "is thought to be desirable and necessary for treating a range of health problems that Western medicine does not treat adequately". In Nigeria, effective medicinal plants in management of various diseases have been documented (Aiyeola and Bello, 2006; Blench and Dendo, 2006a; 2006b; Fasola, 2001; Obute, 2005; Ogunshe et al. 2008; Sofowora, 1993; Weintritt, 2007) including those used for the treatment of opportunistic infections associated with HIVIAIDS (Enwereji, 2008). Weintritt (2007) identified at least 522 medicinal species used in the management of numerous ailments in Nigeria. Medicinal values of insects have also been documented in Nigeria (Banjo et al. 2003; Lawal et al. 2003). Banjo et al (2003) found out that among the ljebu Remos, some insects, when combined with other ingredients, can be used for spiritual protection, preparation of love medicine, management of the eye and ear problems, as well as prevention and control of convulsion in children. In the same vein, arthropods are reportedly used to cure thunderbolt ('magun'), child delivery ('igbebi'), bedwetting ('atole'), yellow fever ('iba apanju') and a host of many other ailments that can not be treated using Western medicines and therapy (Lawal and Banjo, 2007). The table below showcases some African phytomedicinals available in international market.

Furthermore, inadequate accessibility to modern medicines and drugs to treat and manage diseases in middle and low income countries, especially in Africa, may have contributed to the widespread use of TM in these regions especially in poor households. In a recent study by the World Health Organisation and Health Action International ( $\mathrm{HAI}$ ) in 36 low and middle-income countries, drugs were reportedly way beyond the reach of large sections of the populations (Cameron et al. 2008: 6). Therefore, the widespread use of TM in Africa can be attributed to its accessibility. For instance, the ratio of traditional healers to the population in Africa is 1: 500 compared to 1:40 000 medical doctors (see table 2 below for details). Indeed, majority of medical doctors available in Africa are concentrated in urban areas and cities at the expense of rural areas. Therefore, for millions of people in rural areas, native healers remain their health providers.

Besides accessibility to traditional healers, TM provides an avenue through which cultural heritages are preserved and respected. Indeed, TM practice is in line with the socio-cultural and environmental conditions of the people who use it in Africa (Owumi, 2002). TM is sought by Igbo women from Ibiobio indigenous healers in Akwa Ibom State, Nigeria, for i) health conditions that had failed to respond to initial treatment, ii) health conditions stigmatised at communities of origin and iii) health conditions thought to have resulted from supernatural causes (Izugbara, 2005). Okigbo and Mmeka (2006) attribute the use of TM to safety, acceptability, affordability, compatibility and suitability for the treatment of various diseases particularly chronic ones.

In developed countries, on the other hand, factors responsible for the widespread use of TM are beyond accessibility, affordability and cultural compatibility. According to the World Health Organisation (2002a) anxiety about the adverse effects of chemical drugs, improved access to health information, changing values and reduced tolerance of paternalism are some of the factors responsible for the growing demand for CAM in developed countries. 
Table 1: Some Phytomedicinals in the International Market

\begin{tabular}{|c|c|c|c|}
\hline Plant species & Action & Constituents & Countries \\
\hline $\begin{array}{l}\text { Ancistrocladus } \\
\text { abbreviatus }\end{array}$ & Anti-HIV & Michellamine B & Cameroon and Ghana \\
\hline $\begin{array}{l}\text { Corynanthe } \\
\text { pachyceras }\end{array}$ & Male stimulant & $\begin{array}{l}\text { Corynanthidine, } \\
\text { corynanthine, yohimbine. }\end{array}$ & Ghana \\
\hline Tamarindus indica & Insecticides & Pectins & Egypt \\
\hline Rauvolfia vomitoria & $\begin{array}{l}\text { Tranquilizer and } \\
\text { antihypertensive }\end{array}$ & Reserpine, yohimbine & $\begin{array}{l}\text { Nigeria, Zaire, Rwanda, } \\
\text { Mozambique, }\end{array}$ \\
\hline Cinchona succirubra & Anti malarial & Quinine & West African countries \\
\hline Syzigium aromaticum & Dental remedy & Eugenol, terpenoids & $\begin{array}{l}\text { East African countries, } \\
\text { Madagascar }\end{array}$ \\
\hline Agava sisalana & $\begin{array}{l}\text { Corticosteroids and oral } \\
\text { contraceptives }\end{array}$ & Hecogenin & Tanzania \\
\hline $\begin{array}{l}\text { Physostigma } \\
\text { venenosum }\end{array}$ & Opthalmia & Physostigimine (eserine) & $\begin{array}{l}\text { Calabar (Nigeria), Ghana, } \\
\text { Cote D'ivoire }\end{array}$ \\
\hline Prunus africana & Prostate gland hypertrophy & $\begin{array}{l}\text { Sterols, triterpenes, n- } \\
\text { docosanol }\end{array}$ & $\begin{array}{l}\text { Cameroon, Kenya, } \\
\text { Madagascar }\end{array}$ \\
\hline Catharanthus roseus & $\begin{array}{l}\text { Anti-Leukemia and } \\
\text { Hodgkin's disease }\end{array}$ & $\begin{array}{l}\text { Triterpenoids, tannins and } \\
\text { alkaloids }\end{array}$ & Madagascar \\
\hline $\begin{array}{l}\text { Zingiber officinale } \\
\text { (Ginger) }\end{array}$ & $\begin{array}{l}\text { Spice, carminative and } \\
\text { medicinal products }\end{array}$ & Gingerol & Nigeria \\
\hline $\begin{array}{l}\text { Chrysanthemum } \\
\text { cinerariifolium }\end{array}$ & Insecticides & Pyrethrins & $\begin{array}{l}\text { Ghana, Kenya, Rwanda, } \\
\text { Tanzania, South Africa }\end{array}$ \\
\hline
\end{tabular}

Source: Adapted from Okigbo and Mmeka (2006: 86).

Table 2: Sample ratio of THPs compared with the ratio of medical doctors to the population

\begin{tabular}{|l|l|l|}
\hline Countries & $\begin{array}{l}\text { Ratio Of Traditional Practitioners } \\
\text { To Population }\end{array}$ & $\begin{array}{l}\text { Ratio Of Medical Doctors To } \\
\text { Population }\end{array}$ \\
\hline Kenya, Urban (Mathare) & $1: 833$ & $1: 987$ \\
Rural (Kilungu) & $1: 143-345$ & $1: 70000$ \\
\hline Zimbabwe & $1: 600$ & $1: 6250$ \\
\hline Swaziland & $1: 100$ & $1: 10000$ \\
\hline Nigeria (Benin City) & $1: 110$ & $1: 16400$ \\
National Average & No data & $1: 15740$ \\
\hline South Africa (Venda Area) & $1: 700-1200$ & $1: 17400$ \\
\hline Ghana & $1: 200$ & $1: 20000$ \\
\hline Uganda & $1: 700$ & $1: 25000$ \\
\hline Tanzania & $1: 400$ & $1: 33000$ \\
\hline Mozambique & $1: 200$ & $1: 50000$ \\
\hline
\end{tabular}

Source: Chatora, (2003:5). 
Similarly, increase in reported cases of chronic diseases especially in developed countries has been attributed to the growing use of CAM. Although modern treatments are widely available to deal with these ailments, some patients are convinced that they have not provided satisfactory result, hence, the need for alternative or complementary measures. Thorne's et al (2002) study has confirmed the widespread use of CAM among people with chronic illnesses in developed countries. According to Thorne et al (2002: 680) "it appears that people with chronic illness comfortably reconcile the potential benefits of remedies and practices whose foundations derive from radically different worldviews and understandings of human health and illness processes".

Thus, the economic advantages of TM have been outstanding and these have been reported and documented. For instance, annually, TM trade contributes not less than R2.9 billion to the South African economy (Mander et al. 2007). Even in countries where TM is not legally recognised, TM trade has contributed very significantly to the revenue accrued to those countries. For instance, in 1996, about 2.8 million traditional Chinese medicine consultations were reported in Australia. This represented an annual turnover of about 84 million Australian dollars (WHO, 2000a). Table 3 below showcases the phyto-therapeutic sales in the international market. The table shows that the US has the highest phyto-therapeutic sales in the global market in 1997.

Table 3: Phyto-therapeutic Sales in the Global Market in 1997

Table 3: Phyto-therapeutic Sales in the Global Market in 1997
\begin{tabular}{|l|l|}
\hline COUNTRY & SALES \\
\hline Germany & $\$ 3.5$ billion \\
\hline France & $\$ 1.8$ billion \\
\hline Italy & $\$ 700$ million \\
\hline United Kingdom & $\$ 400$ million \\
\hline Spain & $\$ 300$ million \\
\hline Netherlands & $\$ 100$ million \\
\hline *United States of America & $\$ 4.1$ billion \\
\hline
\end{tabular}

*The United States' figures are projections from available data from America on the basis of the 1996 and 1999 figures respectively.

Source: Adapted from Okigbo and Mmeka (2006: 85).

Following the growing demand for TM and the contributions of the medicine to the overall health delivery system particularly in Africa, some authors have suggested that traditional medical system be integrated into the mainstream of health care services to improve accessibility to health care (see Erinosho, 1998, 2005, 2006; Obute, 2005; Odebiyi, 1990; Okigbo and Mmeka, 2006). For example, Obute (2005) asserts that "like all peoples of the world the south-eastern Nigerians have their rich traditional medicine that should be properly organised and formally integrated into the regular healthcare delivery system". This, according to Odebiyi (1990: 341), would improve health care in two folds: enhancement of quality of care and supply of low-cost primary health care. In the same vein, the resolution made at the Regional Committee for Africa, in 2000, recognised the potential of TM for the achievement of universal health coverage in the African Region and suggested accelerated development of local production (WHO, 2002a; 2000c). consequently, the publication of methodologies on research and evaluation of traditional medicine by the World Health Organisation (see WHO, 2000b) and "guidelines for assessing the quality of herbal medicines with reference to contaminants and residues" (see WHO, 2007) were to ensure that people have adequate access to the kinds of information required for effective use of TM and appropriate methodology to be adopted by Member States in their effort to integrate the medicine into the mainstream of health care system.

There are certain problems and challenges to be overcome in order to fully achieve the objective of regulation, standardisation and integration of TM in Africa. First and foremost, the ethnocentric and medicocentric tendencies of the Western hegemonic mentality that are usually paraded by most stakeholders in modern medicine remains a very serious challenge. It is a general belief in medical circle that TM defies scientific procedures in terms of objectivity, measurement, codification and classification. Even then, there are indications that the physical aspects of TM (i.e. the physical ingredients) can be scientifically studied and analysed. In Yoruba culture, for instance, TM comprises of the physical and spiritual realms. While the physical aspects can be subjected to scientific analysis using the conventional scientific methods of investigation, the spiritual realm may not (Oyelakin, 2009). The biggest challenge therefore, is how to scientifically analyse the spiritual aspect of Yoruba TM e.g. "ofo" (incantation). Again, if integrated, who provides training to medical doctors on the ontology, epistemology and the efficacies of African TM given the ethnocentric tendencies in modern medicine? That is, who determines the efficacy and effectiveness of TM given the inherent epistemological and ideological characteristic differences of both medicines? It is part of these difficulties that some scholars suggest that both TM and cosmopolitan medicine be allowed to operate, develop and flourish independent of one another (Konadu, 2008; Oyelakin, 2009). "After all, the western people did not develop their medical aspect in order to integrate it with anyone else. Theirs was to first make themselves and later the rest of the world live a healthy life" (Oyelakin, 2009: 83). From this point of view, if TM is co-opted into the modern medicine, it would further justify and promote the "supremacy" or "superiority" of the cosmopolitan medicine thereby jeopardising the identity and integrity of TM in Africa. 
Another fundamental challenge to TM is the widespread reported cases of fake healers and healing, though, this is not limited to TM practice only. Ebomoyi (1982) observes that since the proficient healers could be rendering beneficial services to a large population, it might be a common place to encounter quacks among the practitioners. In the same vein, Pretorius (1999: 253) notes that "in the current economic climate and amid the concomitant unemployment, there is a marked increase in the ranks of traditional healers, among whom there are, unfortunately, quite a number of charlatans".

Finally, the acceptance of Western religion, education, urbanisation and globalisation phenomena in Africa is affecting the use of TM. Feierman (2002) has noted a 'passionate ambivalence' towards African TM and plants in some segments of the African populations particularly among the educated elites. Teshome-Bahiru (2006) found out that the process of urbanisation has greatly impacted on the use of TM in both rural and urban communities of Addis Ababa, Ethiopia, albeit both in positive and negative ways. Kiringe (2005) detected the impact of Western education and religion on the use of TM. According to Kiringe (2005) the

Introduction of Western culture particularly into rural parts of Africa has had a tremendous negative impact on the role traditional medicine plays. As Western education, Christianity and increased contact with the global community become an integral part of rural communities, taboos, traditions and customs have been affected and in some instances abandoned altogether... (emphasis added).

These challenges notwithstanding, there is increasing evidence that TM would continue to hold sway in both rural and urban communities of Africa even when modern health care facilities are available (Bamidele et al. 2009) to meet wide range of health care needs.

\section{Conclusion and Recommendation}

This paper has examined one of the most burning issues in the international health delivery discourses. The paper argues that traditional medical system used to be the dominant health care system in Africa prior to the period of colonialism. To some extent, colonialism, Western religion and education as well as globalisation phenomenon have negatively affected the perception about TM in Africa, usually among the educated elites. This notwithstanding, the demand for and use of TM have continued to grow not only in Africa but indeed the entire world. Recent studies in health care seeking behaviour, therefore, are increasingly coming to a realisation that traditional practitioners are important players in healing processes especially in developing countries (Hausmann-Muela et al. 2003). Indeed, there are evidences to show that traditional healers have contributed to promoting positive health behaviour and serve as a good referral point to modern health care system. For instance, Osowole et al. (2005) argue that more than 50\% of the traditional healers they studied referred patients at least once to modern health facilities for further treatment. Indeed, traditional healers can provide a lead to scientific breakthrough in modern medicine. Ratzan (2000: 41) notes that the non-Western medicine can provide important links between disease and behaviour as well as effective treatment not found in the Western medicine. Therefore, there is the need for the political will on the part of African leaders to pay serious attention to global trends in TM discourses for the benefit of all and sundry. This would require that both traditional and modern doctors acknowledge their areas of strengths and weaknesses from which they operate and to be genuinely concerned about the difficult but necessary task of being human in order to minimise the current distrust and the perceived paranoid between modern and traditional doctors. There is also an urgent need for appropriate legal frameworks to checkmate the quacks and charlatans in the practice of TM, though such legal frameworks are beginning to unfold in some African countries. It is only when these are genuinely pursued that the objective of regulation, rebranding and standardisation of TM products as well as the proposed cooperation between traditional and modern medicines can be accomplished for the benefit of millions of people who depend on TM in Africa.

\section{References}

1. Achebe, C. (1958), Things Fall Apart. UK: Heinemann Books Ltd.

2. Afisi, O. T. (2009). 'Tracing Contemporary Africa's Conflict Situation to Colonialism: A Breakdown of Communication among Natives'. Philosophical Papers and Reviews, 1(4): 59-66.

3. Aiyeloja, A. A and Bello, O.A. (2006). 'Ethnobotanical Potentials of Common Herbs in Nigeria: A case study of Enugu state' (accessed from http://www.academicjournals.org/err/PDF/Pdf2006/Apr/Aiyeloja and Bello.pdf. on the $18^{\text {th }}$ September, 2009).

4. Amira, OC and Okubadejo, NU. 2007. 'Frequency of Complementary and Alternative Medicine Utilization in Hypertensive Patients Attending an Urban Tertiary Care Centre in Nigeria'. BMC Complementary and Alternative Medicine, 7(30):1-5.

5. Amzat, J. and Abdullahi, A. A. (2008). 'Role of Traditional Healers in the Fight against HIVIAIDS'. EthnoMed, 2(2): 153-159.

6. Bamidele, J. O. Adebimpe, W. O. and Oladele, E. A. (2009). 'Knowledge, Attitude and Use of Alternative Medical Therapy amongst Urban Residents of Osun State, Southwestern Nigeria'. African Journal of Traditional and Complementaryl Alternative Medicine, 6 (3): 281 - 288. 
7. Banjo, A. D. Lawal, O. A. Owolana, O. A. Ashidi, J. S. Dedeke, G. A. Soewu, D. A. Owara, S. O. and Sobowale, O. A. (2003). 'An Ethnozoological Survey Of Insects And Their Allies Among The Remos (Ogun State) South Western Nigeria'. Indilinga African Journal of Indigenous Knowledge System, 2: 61-68.

8. Bello, R. A. (2006). 'Integrating the Traditional and Modern Health Care System in Nigeria: A Policy Option for Better Access to Health Care Delivery'. In Saliu, H. Jimoh, A. And Arosanyin, T. (eds.), The National Question and Some Selected Topical Issues on Nigeria. Ibadan: Vantage Publishers.

9. Blench R. and Dendo M. (2006a). 'Fulfulde names for plants and trees in Nigeria Cameroun, Chad and Niger', Cambridge, (accessed from http://www.rogerblench. info/Ethnosciencedata/Fulfulde Plant names.pdf on the $8^{\text {th }}$ September, 2009).

10. Cameron, A. Ewen, M. Ross-Degnan, D. Ball, D. Laing, R. (2008). Medicine Prices, Availability, and Affordability in 36 Developing and Middle-Income Countries: A Secondary Analysis. Geneva: The World Health.

11. Carpentier, L. Prazuck, T. Vincent-Ballereau, F. Ouedraogo, L. T. and Lafaix, C. (1995). 'Choice of Traditional of Modern Treatment in West Burkina Faso. World Health Forum. 16: 198-210.

12. Chatora, R. (2003). 'An Overview of the Traditional Medicine Situation in the African Region'. African Health Monitor, 4(1): 4-7.

13. Cook, C. T. (2009). 'Sangomas: Problem or Solution for South Africa's Health Care System'. Journal of the National Medical Association, 101(3): 261-265.

14. Curtin, P. D. (1989). Death by Migration: Europe's Encounter with the Tropical World in the Eighteenth Century. London: Cambridge University Press.

15. Curtin, P. D (1998). Disease and Empire: The Health of European Troops in the Conquest of Africa. London: Cambridge University Press.

16. Ebomoyi, E. W. (2009). 'Genomics in Traditional African Healing and Strategies to Integrate Traditional Healers into Western-Type Health Care Services- A Retrospective Study'. Researcher, 1(6): 69-79.

17. Enwereji, E. E. (2008). 'Important Medicinal Plants for Treating HIVIAIDS Opportunistic Infections in Nigeria'. Middle East Journal of Family Medicine, 6(3): 21-28.

18. Erinosho, O. A. (1998). Health Sociology for Universities, Colleges and Health Related Institutions. Ibadan: Sam Bookman.

19. Erinosho, O. A. (2005). Sociology for Medical, Nursing, and Allied Professions in Nigeria. Abuja: Bulwark Consult.

20. Erinosho, O. A. (2006). Health Sociology for Universities, Colleges and Health Related Institutions.

Ibadan: Abuja: Bulwark Consult. Reprint.

21. Fasola, T. R. (2001). 'Cultural Application of Medicinal Plants in Nigeria'. A Paper Presented at the 11th Congress of Pan-African Association for Prehistory and Related Fields that took place February 7-11, Bamako, Mali.

22. FMOH. (2004). 'Healthcare in Nigeria'. Annual Bulletin, Federal Ministry of Health. Abuja, Nigeria.

23. Feierman, S. (2002). 'Traditional Medicine in Africa: Colonial Transformations'. New York Academy of Medicine. March, 13. Reported by Carter, GM. The Foundation for the Integrative AIDS Research.

24. Hassim, A. Heywood, M. and Berger, J. (No Date). 'Health and Democracy' (accessed from http://www.alp.org.za on the $12^{\text {th }}$ of January, 2010).

25. Hausmann-Muela, S. Ribera, J. M. And Nyamonga, I. (2003). 'Health Seeking Behaviour and the Health System Response'. DCPP Working Paper, 14:1-37.

26. Hillenbrand, E. (2006). 'Improving Traditional-Conventional Medicine Collaboration: Perspectives from Cameroonian Traditional Practitioners'. Nordic Journal of African Studies, 15(1): 1-15.

27. Izugbara, CO. Etukudoh, IW. and Brown, AS. (2005). 'Transethnic Itineraries for Ethnomedical Therapies in Nigeria: Igbo Women Seeking Ibibio Cures'. Health and Place, 11: 1-14.

28. Jegede, A. S. (1996). 'Social Epidemiology'. In Oke, E.A. Owumi, B.E. (eds.) Readings in Medical Sociology. Ibadan: Resource Development and Management Services (RDMS).

29. Kiringe, JW. 2005. 'Ecological and Anthropological Threats to Ethno-Medicinal Plant Resources and their Utilization in Maasai Communal Ranches in the Amboseli Region of Kenya'. Ethnobotany Research and Applications, 3:231-241.

30. Konadu, K. (2008). 'Medicine and Anthropology in Twentieth Century Africa: Akan Medicine and Encounters with (Medical) Anthropology'. African Studies Quarterly, 10 (2\&3) (accessed from http://africa.ufl.edu/asq/v10/v10i2a3.htm on the 17th February, 2010).

31. Lawal, O. A., and Banjo, A. D., and Junaid, S.O., (2003). 'A Survey of Ethnozoological Knowledge Of Honey Bees (Apis Mellifera) in ljebu Division Of South West Nigeria'. Indilinga Afr. Journal of Indigenous Knowledge System, 2:75-87.

32. Lawal, O. A. and Banjo, A. D. (2007). 'Survey for the Usage of Arthropods in Traditional Medicine in Southwest Nigeria'. Journal of Entomology, 4(2): 104-112.

33. Lekotjolo, N. (2009). 'Wits Starts Training of first 100 Sangomas this Year'. The Times, 15 July: 8. 
34. Makundi, E. A. Malebo, H. M. Mhame, P. Kitua, A. Y. and Warsame, M. (2006). 'Role of Traditional Healers in the Management of Severe Malaria among Children below Five Years of Age: the Ccase of Kilosa and Handeni Districts, Tanzania'. Malaria Journal, 5(58): 1-9.

35. Mander, M., Ntuli, L., Diederichs, N., and Mavundla, K., (2007).Economics of the Traditional Medicine Trade in South Africa' (accessed from http://www.hst.org.za/uploads/files/chap13_07 on 27 March, 2009).

36. Mapara, J. (2009). 'Indigenous Knowledge Systems in Zimbabwe: Juxtaposing Postcolonial Theory'. The Journal of Pan African Studies, 3(1): 139-155.

37. Millar, D., (2004). 'Interfacing Two Knowledge Systems: Local Knowledge and Science in Africa'. Paper for the Compas Panel in the Conference: Bridging Scales and Epistemologies: Linking Local Knowledge with Global Science in Multi-Scale Assessments. Alexandria March.

38. Nevin, T. (2001). 'Day of the Sangoma'. African Business, 261:16-18.

39. Obute, GC. 2005. 'Ethnomedicinal Plant Resources of South Eastern Nigeria' (accessed from http://www.siu.edu/ ebl/leaflets/-obute.htm. on the 18th September, 2009).

40. Odebiyi, A. I. (1990). 'Western Trained Nurses Assessment of the Different Categories of Traditional Healers in South Western Nigeria'. International Journal of Nursing Studies. 27(4): 333-342.

41. Offiong, D. A. 1980. Imperialism and Dependency: Obstacles to African Development. Enugu, Nigeria: Fourth Dimension Publishers.

42. Ogunshe, A. A. O. Lawal, O. A. and Iheakanwa, C. I. (2008). 'Effects of Simulated Preparations of Plants used in Nigerian Traditional Medicine on Candida spp. Associated with Vaginal Candidiasis'. Ethnobotany Research and Applications, 6:373-383.

43. Oke, E .A. (1995). 'Traditional Health Services: An Investigation of Providers and the Level and Pattern of Utilization among the Yoruba'. Ibadan Sociological Series, No. 1: 2-5.

44. Okigbo, R. N., and Mmeka, E. C. (2006). 'An Appraisal of Phytomedicine in Africa'. KMITL Science and Technology Journal, 6(2): 83-94.

45. Osowole, O. Ajaiyeoba, E. Bolaji, Akinboye, D. Fawole, O. Gbotosho, G. Ogbole, O. Ashidi, J. Abiodun, O. Falade, C. Sama, W. Oladepo, O. Itiola, O. Oduola, A. (2005). 'A Survey of Treatment Practices For Febrile Illnesses Among Traditional Healers In The Nigerian Middle Belt Zone'. African Journal of Traditional and Complementary/Alternative Medicine, 2 (3): 337 - 344.

46. Owumi, B. E. (2002). 'The Political Economy of Maternal and Child Health in Africa'. In Isiugho-Abanihe, U.C., Isamah, A.N., Adesina, J.O., (eds.) Currents and Perspectives in Sociology, Ibadan: Malthouse Press Limited.

47. Oyelakin R. T. (2009). 'Yoruba Traditional Medicine and the Challenge of Integration'. The Journal of Pan African Studies, 3(3): 73-90.

48. Paul, J., (1977). Medicine and Imperialism in Morocco. MERIP Reports, 60: 3-12.

49. Pretorius, E. 1999. 'Traditional Healers'. South African Health Review. Health Systems Trust. Durban, 5th Edition, 249-256.

50. Ratzan, S. C. Filerman, G. L. And LeSar, J. W. (2000). 'Attaining Global Health: Challenges and Opportunities'. Population Bulletin, 5(1):1-48.

51. Roberts, H. (2001). 'ACCRA: A Way Forward for Mental Health Care in Ghana? Lancet, 357 (9271): 1859.

52. Rodney, W. 1972. How Europe Underdeveloped Africa. London: Bogle-L'Ouverture Publications.

53. Romero-Daza, N., (2002). 'Traditional Medicine in Africa'. Annals of the American Academy of Political and Social Science, 583: 173-176.

54. Sofowora, A. (1993). Medicinal Plants and Traditional Medicine in Africa. Ibadan, Nigeria: Spectrum Books Ltd.

55. Taiwo, O. (1993). 'Colonialism and Its Aftermath: The Crisis of Knowledge Production'. Callaloo, 16(4): 891908.

56. Teshome-Bahiru, W. 2006. 'Impacts of Urbanisation on the Traditional Medicine of Ethiopia'. Anthropologist, 8(1): 43-52.

57. The Sun News. 2010. Lagos. Accessed from http://www.thesunnewsonline.com on the $16^{\text {th }}$ of June, 2010).

58. Thorne, S. Paterson, B. Russell, C. Schultz, A. (2002). 'Complementary/alternative Medicine in Chronic Illness as Informed Self-Care Decision Making'. International Journal of Nursing Studies, 39: 671-683.

59. Weintritt, J. (2007). 'The Use of Plants in Traditional Medicine in Nigeria'. Africana Bulletin. Warszawa. 119131.

60. Wetzel, M.S. Einsenberg, D.M. and Kaptchuk, T.J. (1998). 'Courses Involving Complementary and Alternative Medicine at US Medical Schools'. JAMA, 280: 784-787.

61. WHO, (2000a). Traditional and Modern Medicine: Harmonising the two Approaches. Western Pacific Region. Geneva: World Health Organisation.

62. WHO. (2000b). General Guidelines for Methodologies on Research and Evaluation of Traditional Medicine. Geneva: World Health Organisation.

63. WHO. (2000c). Promoting the Role of Traditional Medicine in Health Systems: a Strategy for the African Region 2001-2010. Harare: World Health Organization. Document Reference AFR/RC50/Doc.9/R. 
64. WHO. (2001). Legal Status of Traditional Medicine and Complementary/Alternative Medicine: A Worldwide Review. Geneva: World Health Organisation.

65. WHO. (2002a). WHO Traditional Medicine Strategy 2002 -2005. Geneva: World Health Organisation.

66. WHO. (2002b). Traditional Medicine- Growing Needs and Potential. Geneva: World Health Organisation.

67. WHO. (2007). WHO Guidelines for Assessing Quality of Herbal Medicines with Reference to Contaminants and Residues. Geneva: World Health Organisation 